\title{
Connecting Graduate Students Across the World with Research Web-Conferences
}

\author{
Reima Saado Al-Jarf \\ King Saud University \\ Saudi Arabia \\ Email: reima.al.jarf [AT] gmail.com
}

\begin{abstract}
This article describes a series of training web-conferences in which graduate students majoring in linguistics in Australia, UK, USA and Saudi Arabia participated. The web-conferences aimed at developing graduate students' electronic searching skills in linguistics, to introduce them to latest trends and developments in linguistic research, and to communicate with expert linguists worldwide. They were initiated, organized and hosted by the Saudi Linguists' Society (SAL) created a Saudi graduate student studying in the U.K. Since SAL has a limited budget, free web-conferencing software, such as PalTalk, Skype, How-to Geek and WEbex, were tried out. Graduate students could register in the web-conferences for free. SAL's web-conferencing coordinator who was a graduate student in Australia invited the speakers, selected the web-conferencing theme, prepared the web-conference poster, announced them in the SAL website and on its Facebook page, scheduled them, and registered the participants. Steps in preparing for and conducting the training web-conferences are given. Participants' views on the benefits and shortcomings of training web-conferences are reported. Recommendations for conducting effective training webconferences and for extending free web-conferencing and webinar tools to other educational settings in Saudi Arabia are given. In general, the participants found the training web-conferences cost-effective and beneficial.
\end{abstract}

Keywords - web-conferences, online training, synchronous online training, electronic searching web-conferences, graduate training, online training workshops

\section{INTRODUCTION}

Rapid advancements in information and communication technologies have enabled educational institutions, organizations and government agencies to use new forms of training to enhance performance, learning and instruction. Webinars, and interactive web-conferences are common training tools currently used to share knowledge, facilitate communication and collaboration among students and instructors, employers and employees and specialist in different locations.

Results of several studies have shown that webinars, web conferences, and streaming media have several benefits. For example, in-service teachers from primary, secondary and vocational schools and science and art centers in Turkey, who participated in online in-service education and training (INSET) activities reported that those activities helped them overcome time and place dependency, resolved accommodation and transportation issues, and used resources more effectively (Kokoc, Ozlu, Cimer \& Karal, 2011). Similarly, Forrester (2009) indicated that web-conferencing platforms help educators in different countries collaborate in real time. All that teachers, school counselors, and administrators need is to put their headsets on, align their time zone, and log on to meet and learn from international educators. Thus, webconferences and webinars are a cost-efficient way to train students, teachers and employees (Wolf, 2006). There is no need to pay facility expenses and hire qualified professors. Busy professionals not willing to travel to a physical classroom make the decision to provide the cost-effective infrastructure of online learning (Bandy (2010).

In addition, web-conferencing enables instant sharing and access of multimedia-supported lectures, question-andanswer sessions, voice and video group work, and archived resource materials-- all in a geo-distributed mode (Foreman \& Jenkins, 2005). Streaming video and audio play an important role in delivering course materials to online students and bring courses alive by allowing students to use their visual and auditory senses to learn highly complex concepts and difficult procedures (Hartsell and Yuen, 2006).

In a study by Montgomery (2009), embedding a librarian in a course enhanced student learning by connecting students with reliable resources, providing instruction via online webinars, giving them an interactive learning experience, and using webinars as a way to be where users and resources are. 
Moreover, web-conferencing is an effective tool for creating constructivist learning environments that enable adult learners to engage in a continuous, collaborative process of building and sharing knowledge and understanding (Curran, Kirby, Parsons and Lockyer (2003). In New Zealand, the University of Waikato used web-based computer conferencing to support student knowledge construction and collaborative group work (Johnson, Bishop, Holt, Stirling, and Zane, 2001). In rural areas, it promoted knowledge construction and sharing among student participants. The integration of web-conferencing in program and course components proved to be a useful "survival tool" for rural special educators, as it helped them overcome geographic barriers and professional isolation (Chapman and Knapczyk, 2003).

Furthermore, web-based conferencing enhanced inter-personal communication among students and instructors in graduate courses, helped resolve problems related to course content and procedures, and provided instructors with feedback on the course (Quilter and Chester, 2001). It also made communication easier among pre-service teachers outside their classroom when discussing teaching issues from their field experiences. Web-conferencing and case-based instruction fostered quality discourse and promoted students' critical thinking skills (Angeli, Valanides and Bonk, 2003).

\section{LITERATURE REVIEW}

Web-conferences, webinars, and online training have been the focus of numerous studies in the literature which have investigated some contexts in which they are being used and the effects of their use on learning and training. For example, Loudon and Sharp (2006) used an automated system that allowed students to replay both audio and video lectures from a large non-majors' organic chemistry class as streaming RealMedia. The system required no technical intervention and was virtually transparent to the instructor. It allowed the students to the online class review at any time. Assessment showed that usage grew from about one-third of the class when RealMedia was first introduced to about twothirds of the class two years later. $93 \%$ of the students who used RealMedia rated it extremely useful or somewhat useful.

A survey of 54 teachers from urban, suburban, and rural areas in southern and central Indiana, who evaluated six design considerations for using web-conferences in teaching emotional/behavioral disorders in an on-line introductory methods course indicated that web-conferencing was an effective platform for offering coursework and other professional development experiences to mid-career student-teachers (Knapczyk, Frey and Wall-Marencik, 2005).

At a regional Australian university with a significant distance population, graduate students enrolled in education courses were linked using a web-conferencing software. The students participated in an interactive and collaborative conference activity, communicated via audio, video and text and shared the whiteboard. The web-conferencing software enabled teachers and students to engage actively across diverse locations, supporting a student-centered approach and greater flexibility in terms of where, when and how students learn (Reushle and Loch, 2008).

In the business field, Wynter-Wellington (2010) evaluated the effectiveness of an interactive online training course for a placement and business service. The researchers also examined the extent to which the course helped clientapplicants understand job application and interview processes. The majority of job applicants reported that the online training course was excellent or very good in preparing them for a successful job interview. In another study, 101 nonprofit staff from a human services organization attended online training sessions using a simulated training announcement and the Technology Acceptance Model. The participants reported the usefulness, ease of use, positive attitudes towards the online training provided and expressed their intentions to attend similar online training sessions in the future (Kingery, 2009).

Not only has online training been used with adults, but it has also been used with teenagers. A total of 904 students in grades 8 and 9 were enrolled an Internet-delivered stress-prevention program as a possible alternative for school-based implementation of mental health program. The results showed a considerable knowledge gain among participants in the online-program. The number of positive cognitions in stress-evoking situations also increased. Although onlineprevention stress-prevention program cannot completely substitute the school-based face-to-face-training, it can be seen as an effective and economic complement to conventional methods of mental health promotion (Fridrici \& Lohaus, 2009).

Webinars are also being used by the Louisiana Virtual School, run and funded by the Louisiana Department of Education, with 6,000 students, 115 instructors, and 450 site facilitators spread across 300 schools in 72 districts. Webinars play a vital role in the school's ability to meet the challenges of teaching students and facilitating teacher and administrator development. Webinar technologies make it easier for school administrators to expand professional development so that instructors have the necessary skills for delivering the new online curriculum, engage students in exciting yet practical matrial, and effectively communicate with faculty and staff members (Grant, 2009). 
The above studies show that web-conferencing was successfully used in some university, school and business settings to promote students, teachers, and employee performance.

\section{NEED FOR STUDY}

Although, the number of educational institutions organizations and government agencies conducting webconferences, webinars, and online training for students, pre- and in-service teachers, librarians, and other professionals is increasing, training web-conferences are rarely conducted in Saudi Arabia to meet the educational needs of students, particularly graduate students. Many Saudi graduate students, especially those majoring in linguistics, applied linguistics and TEFL, have difficulties in preparing their theses such as selecting a topic, locating and accessing relevant library resources related to the topic of interest to them, and unfamiliarity with trends in linguistic research. Many do not receive sufficient training in locating references and resources from their supervisors, and do not have the chance to meet and consult with experts and specialists in the field either.

To develop graduate students' electronic searching skills in linguistics, to introduce them to latest trends and developments in linguistic research, and to develop their ability to communicate and interact with specialists in linguistics worldwide, a series of training web-conferences in electronic searching skills was initiated, organized and hosted by the Saudi Linguists' Society (SAL), a society that was created by a Saudi Ph.D. student studying in the UK and whose members are student linguists studying in diverse locations worldwide. SAL has a website and a Facebook page.

As an experienced instructor and researcher, the author was invited to deliver few web-conferences in electronic searching to Saudi graduate students majoring in linguistics and applied linguistics worldwide. The electronic searching web-conferences proved to be beneficial to the students despite some technical obstacles. To publicize the use of training web-conferences, the present study aims to describe the following: (i) steps to be followed in preparing for and conducting training web-conferences; (ii) the technical requirements for conducting training web-conferences; (iii) technical difficulties that might face web-conferencing presenters and participating students and how they can be overcome; (iv) the participants' views on the benefits and shortcomings of training web-conferences; (v) criteria for conducting effective training web-conferences.

\section{SIGNIFICANCE OF STUDY}

The study will help gain a better understanding of electronic learning environments. It will give some initial recommendations to the Saudi Ministry of Higher Education and Saudi university administrations on the adoption of web-conferenced to support learning and teaching. It gives recommendations for conducting training web-conferences using free web-conferencing software and for extending free web-conferencing and webinar tools to other educational settings in a variety of disciplines, especially where there is shortage in specialized and qualified instructors. It shows how instructors and students can connect in an easy way. It sheds light on the internal and external barriers facing training web-conferences. It also gives a set of guidelines for the best practices in training web-conferences. Results of the study provide meaningful guidance for both researchers and practitioners responsible for the design and implementation of synchronous online training courses.

\section{DEFINITION OF TERMS}

Web conferencing, webinars, and streaming media are very common terms used by e-learning and distance learning specialists these days. Each of which is defined below.

Web conferencing ${ }^{1}$ is a tool that allows conferencing events to be shared by distant locations. Web-conferences are utilized in meetings, training events, lectures, seminars or short presentations from any computer. It allows realtime point-to-point communication as well as multicast communications from one sender to many receivers. Webconferencing is made possible by Internet TCP/IP connections. It enables users to share text, voice and video chat simultaneously across geographically distant locations. The web-conferencing technology was first introduced by Starlight Networks in the late 1990's. Some of the popular web-conferencing software nowadays are Skype, WebEx, Elluminate and AnyMeeting.

A webinar ${ }^{2}$ (short for web-based seminar) is a presentation, lecture, workshop or seminar transmitted over the Internet. A key feature of a webinar is the ability to give, receive, share and discuss information. By contrast, in Webcast, data are transmitted one way and interaction between the presenter and the audience is not allowed.

\footnotetext{
${ }^{1}$ http://en.wikipedia.org/wiki/Web_conferencing

2 http://www.webopedia.com/TERM/W/Webinar.html
} 
Interactive web-conferences $^{\mathbf{3}}$ utilize electronic meeting systems (EMS) which provide brainstorming, structured discussions, making comments, a range of voting methods, typically with optional anonymity. However, EMS do not provide screen sharing or voice conferencing. Some EMS can control web-conferencing sessions.

Streaming media ${ }^{4}$ are multimedia that is constantly delivered and presented by a provider and received by to an end-user. Internet TV is a common form of streamed media. In addition to video and audio, the term "streaming media" can apply to real-time text, live closed captioning, stock ticker which are all considered "streaming text".

Live streaming $\mathbf{5}^{\mathbf{5}}$ means delivering live over the Internet. It involves a camera for the media, an encoder to digitize the content, a media publisher, and a content delivery network to distribute and deliver the content.

\section{METHODOLOGY}

\subsection{Participants}

Participants of the electronic searching web-conferences consisted of 20 Saudi graduate students majoring in linguistics, applied linguistics or TEFL in Australia, UK, USA and Saudi Arabia. All of the participants were members of SAL. They all registered in the web-conferences on a voluntary basis as it was not part of any formal graduate course.

The generalizability of the results of this study is limited due to the lack of randomness in selecting the participants as they are all members of SAL, and due to the small student sample that attended the web-conferences.

\subsection{The Web-conferences}

Several interactive, training web-conferences were scheduled by SAL members. Topics were chosen based on the students' research needs and interests and in consultation with the presenters, i.e. participating professors. Examples of the topics chosen are: How to search for references online, how to conduct an experiment, the needs for discourse analysis in an Arabic and Muslim context, conducting critical discourse analysis, postdoctoral research and publication and others. The web-conferences lasted between 1:30-3 hours including at least 30 minutes per web-conference for questions and answers. The web-conferencing schedule was set depending on the instructors. Several free webconferencing software that work on any platform (PC, Mac, Linux, or Solaris), that require no hardware installation or software maintenance, and that allow desktop sharing were tried out such as PalTalk, Skype, How-to Geek, WEbex (See Figure 1).

The founder of SAL and coordinator of the web-conferences expressed the objective of the web-conferences as follows:

Online seminars allow us (graduate students) to attend classes given by professors in different universities in different fields. We need such encounters with these professors to motivate us and benefit from their experience...through these seminars we may highlight the importance of research and encourage people to work together and start research projects that will benefit the society.

\footnotetext{
${ }^{3}$ http://www.webopedia.com/TERM/W/Webinar.html

4 http://en.wikipedia.org/wiki/Streaming_media

5 http://en.wikipedia.org/wiki/Streaming_media
} 


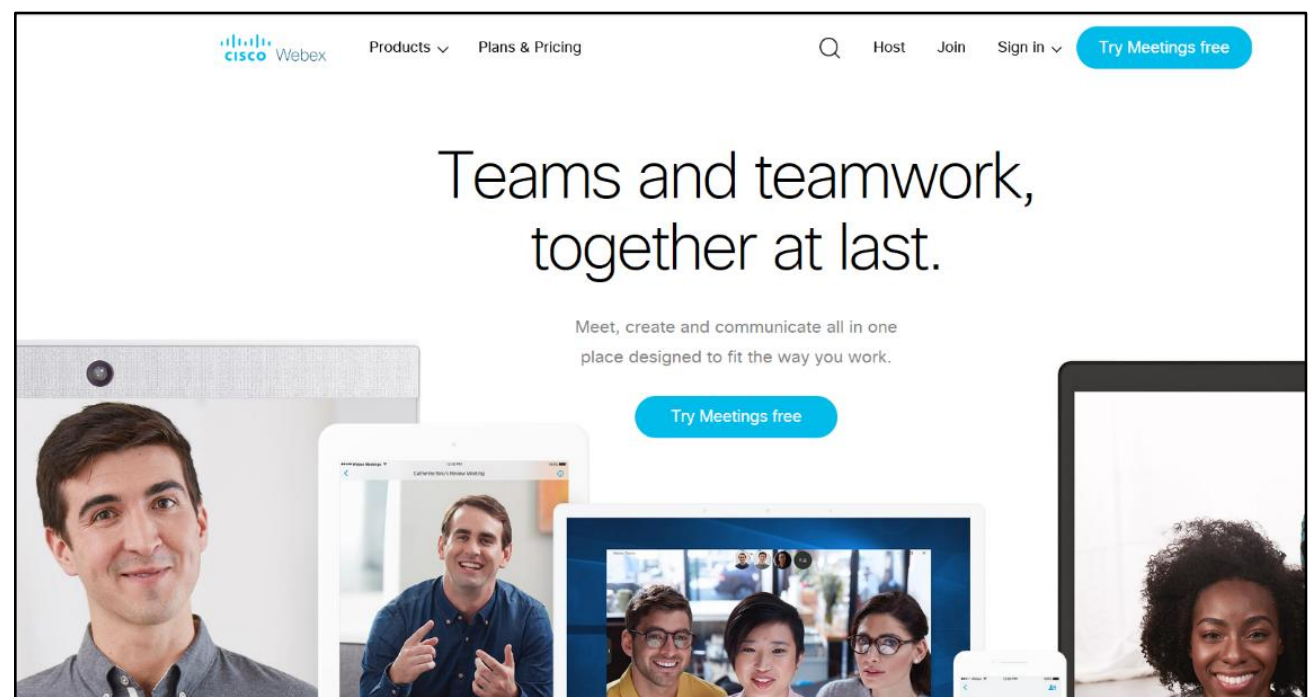

6.3 Training Objectives, Content and Tasks

Figure 1: The Main Page of WebEx Web conferencing Software

As an example, the objectives, content and tasks of the training web-conferences that the author gave about "Electronic Searching Skills" are given below. The aims of the electronic searching web-conferences were to enable graduate students to:

- $\quad$ select search terms, narrow or broaden them.

- connect search terms with Boolean operators such as "and, or, not" or enclosing search terms in quotation marks when searching Google or Google Scholar.

- understand and use basic electronic searching commands and common abbreviations such as "simple" and "advanced search", AU (author), AB (abstract), SU (subject), KW (keyword).

- $\quad$ use search terms to locate documents in specialized databases such as Dissertation Abstracts, Linguistics and Language Behavior Abstracts (LLBA), ERIC, Google Scholar, Google Books, Questia.

- components of the database homepage.

- $\quad$ searching by author, title, keyword or descriptor.

- $\quad$ selecting the document type.

- marking the relevant records.

- $\quad$ selecting the display options.

- viewing and evaluating the search results.

- how to narrow, broaden, or change the search terms to get more accurate and relevant results, i.e. documents.

- $\quad$ saving, printing or e-mailing the search results.

- $\quad$ how to document the references cited using APA style.

\subsection{Procedures}

SAL graduate student members selected, contacted and invited the guest speakers, selected the workshop themes, prepared the workshop poster, announced the web-conferences online, scheduled them and registered participating students. Registration in the web-conferences was free for graduate students. Since SAL has a limited budget, free webconferencing software were tried out such as PalTalk, Skype, How-to Geek, WEbex.

The author and a student tried out the web-conferencing software before going live. At the beginning of the session, the author gave the students a brainstorming task that required them to select a research topic of interest to them and make a list of search terms related to it consisting of single-word terms or compounds. The students' topics and search terms were used to demonstrate the electronic searching steps in each database or search engine and to keep the students interested and engaged. She would call on each student, once in a while, to answer or explain something, to make sure they were following, and were able to understand the information presented.

\subsection{Data Collection}

At the end of the training sessions, the participants were surveyed. They were asked about the benefits and shortcomings of the web-conferences they have attended, and whether they found them useful. The students' chat messages containing their questions and comments during the web-conferences, and technical problems faced were 
examined and analyzed. The author also kept a log on how the web-conferences went on, and the technical problems faced.

\subsection{Data Analysis}

The participants' views on the web-conferences and the technical difficulties faced by the presenters and participating students and how they were overcome were sorted out and analyzed qualitatively.

\section{RESULTS}

\subsection{Benefits of the Training Web-conferences}

Responses to the survey indicated that all of the participants considered the web-conferences extremely useful and would like to join any web-conferences to be conducted in the future. The web-conferences helped them overcome barriers of time, and geographic and professional isolation. They gave them a chance to meet and learn in real time from experts in different parts of the world. They gave them a chance to get to know and collaborate with graduate students studying the same major in other countries and other universities. The participants could join the web-conferences from home, and did not have to travel physically to a particular location. Thus, they saved travel time and expenses.

Despite the technical problems, the web-conferences helped the students participate in interactive and collaborative educational activities, and communicate via audio, text, and video, share the presenter's screen, re-play the recorded workshop which was made available in the SAL archived resource materials. The web-conferences enabled the instant sharing and access of multimedia-supported lectures and question-and-answer sessions.

The SAL founder and workshop coordinator indicated that due to their limited budged and lack of financial support, the web-conferences conducted with free web-conferencing software are a cost-efficient way to train graduate students in issues related to their major area of study. SAL did not pay for the software, nor for any meeting facilities.

Survey findings also revealed that the web-conferences provided a constructivist learning environment, and a studentcentered approach that focused on participants' needs and interests in linguistics research. The participants engage in a continuous, collaborative process of building and shaping knowledge about linguistic research, theory and practice. Their comments revealed a considerable knowledge gain, as a result of attending the training web-conferences. They indicated that the author had the skills to deliver practical information about locating references online, engaging attendees in exciting and practical information, and was able to effectively communicate with them. Mohammed wrote:

it was a great experience and wonderful info we got from Prof. Reima.

Ahlam, the coordinator of the web-conferences and who is a Ph.D. student in Australia, added:

Prof. Reima's seminar was important especially to those who did not have an idea about libraries. Online libraries are new to our students and searching any database sometimes could be confusing. All of the feedback was positive, and attendees recommended the seminar to other students. Some of the students who attended the seminar were BA (senior) students who had a project, and they needed to use Umm Alqura online library. They were happy, and they contacted me to tell me that Prof. Reima made it easy for them to look for references for their projects. They told me that they were taking notes and wrote the name of the databases Prof. Reima suggested.

Graduate students were excited about the web-conferences and were eager to join them. However, SAL organizers were not willing to register more than 20 participants in each web-conference to keep it manageable, to give each participant a chance to ask questions and receive answers, and to enable the web-conferences presenter to attend to students individually. Ahlam, commented:

we had waiting lists because we could not accept more than 20 students, and this is due to the capacity of the online seminar room. That's why we planned to hold some of the seminars under the request of the students.

Findings of the present study are consistent with findings of other studies in the literature, mentioned above such as Kear, Chetwynd, Williams \& Donelan (2012); Kokoc, Ozlu, Cimer \& Karal (2011); Forrester (2009); Bandy (2010); Kingery (2009); Fridrici \& Lohaus (2009); Grant, 2009); Skylar (2009); Reushle \& Loch (2008); Hartsell \& Yuen(2006); Wolf (2006); Loudon \& Sharp (2006); Knapczyk, Frey \& Wall-Marencik (2005); Foreman \& Jenkins (2005); Curran, Kirby, Parsons \& Lockyer (2003); Chapman \& Knapczyk (2003); and Johnson, Bishop, Holt, Stirling, $\&$ Zane (2001) in which participants found that online training effective and beneficial. 


\subsection{Shortcomings of the Training Web-conferences}

Responses to the survey from the participants revelaed some technical obstacles while preparing for the webconferences. Several web-conferencing software were tried out: PalTalk, Skype, Hot to Geek and WebEx. The author had a screen and desktop sharing problem when using PalTak and Skype. In addition, some students were disconnected, the author suffered from slow connection and slow browsing, and there was a buzzing sound throughout the session conducted via How-to-Geek. Ahlam noted:

The quality of the voice due to the poor connection on the end of the students or the speaker was among the challenges and shortcomings that we could not overcome. Hopefully, the third workshop went on fine with WebEx. As a coordinator of the web-conferences,

In the first few sessions, there was no technical support available to help with emerging problems. However, starting from the third session, the coordinator managed to have technical support available online from a graduate student majoring in IT.

Some participants had no prior experience using the web-conferencing software. To make it easy for the participants to use the software, they were e-mailed a link and login instructions. They did not have to download anything; they only had to click on a link to go directly to the main page. At the beginning of, and throughout the session, the author and coordinator had to prompt the students and direct them.

The author had to work with several screens: A Google screen, a university library screen that shows a list of databases and a database screen, in addition to the chat screen. She also had to deal with multiple online tasks such as switching between websites, waiting for the students to respond to an assigned task, calling on the students individually to respond to a question, following up the text chat, creating some interaction especially because some participants were hesitant to use the video, reconnecting and re-logging and into the library electronic resources.

Despite the positive effects of such practice on electronic searching skill improvement, being a web-conference presenter, the author thinks that web-conferences lack the opportunity for further skill practice on the part of the participants, as no follow-up asynchronous activities were organized through a complementary online discussion forum or blog.

Few students left the session due to the poor sound quality, or because they had other commitments. Some students could not attend the first session because of the lack of time available both at school and at home.

Another difficulty was setting a presentation time that suits the presenter who lived in Saudi Arabia and students living in Australia, UK and USA. Samia indicated:

Because of the different time zones of the students and the speakers, sometimes it was inconvenient for some students to attend the seminar.

Finally, the web-conferences were organized by volunteer students belonging to a volunteer students' organization that is funded by the students themselves. They could not subscribe to a premium version of a web-conferencing software, nor rent a chat-room that costs about SR6000 for lack of financial support and inadequate funding. Here again, Sara says:

... and because we are not supported financially, we could not buy expensive software designed for webinars.

Planning, managing and following up the web-conferences constituted an extra burden on the student-organizer's time, who was a Ph.D. student working on her thesis. Ahlam commented:

I was too busy, and I had to take care of a few things around, none of the members had time to take care of the seminars.

Shortcomings of the training web-conferences reported in the present study are consistent with the types of barriers to training web-conferences reported by other prior studies in other contexts such as: Kear, Chetwynd, Williams \& Donelan (2012); Supanakorn-Davila \& Bolliger (2012); Ghosh \& Githens (2011); Coffey (2010); Sitzmann, Ely, Bell \& Bauer (2010); Long, Dubois \& Faley (2009); Daytner, Robinson, Schneider \& Johanson (2009); and Doo (2006).

\section{CONCLUSION AND RECOMMENDATIONS}

The use of web conferencing, webinars and training web-conferences in teaching and learning is a common practice in education today. The series of web-conferences in which Saudi students studying in the Australia, USA, UK and Saudi Arabia were connected and participated proved to be effective, beneficial and enhanced the students' linguistics shared 
knowledge and electronic searching skills despite the technical difficulties encountered, and the time wasted trying to fix the problems.

For training web-conferences to be effective to the students and trainees, the web-conferencing software chosen must meet several conditions such as: Desktop sharing, video and audio conferencing, text chatting and messaging, and should work on any platform. The presenter and a student can try out the web-conferencing software before conducting the training session. There should always be alternative web-conferencing software in standby, in case an unexpected problem happens. Availability of IT support specialists for providing adequate support to the trainers and trainees before, during and after the workshop is necessary.

Web-conferences should meet students' needs, work/study schedule, and location. The subject matter, the activity design, and the choice of interface should be chosen carefully as they affect interaction and collaboration during the online workshop (Cereijo, 2006; Bower \& Hedberg, 2010). Training web-conferences should be incorporated with asynchronous online discussion to foster learning and to ensure extra practice (Lin \& Chiu, 2008; Seufferheld \& Scagnoli, 2011). Trainer-controlled interactivity should be provided to enhance trainee perceptions of the trainer's credibility by allowing student-to-content, interface and instructor interaction (Stephens \& Mottet (2008); Contreras \& Dolan (2006).

Faculty conducting the workshop should be trained to teach online using a particular delivery system, i.e. webconferencing software with which they will be teaching (Wolf, 2006).

Sufficient funds should be provided to subscribe to an efficient delivery system or web-conference software such as Eluminate, Any Meeting, or Adobe Connect. The participants preferred to get financial support from the Saudi Ministry of Higher Education and gave some reasons. Ahlam suggested:

We need to be supported financially.

Bashayer also suggested:

The ministry can buy such webinar software so academics with the help of graduate students can arrange such seminars.

Fadwa pointed out:

I don't mean to conduct these seminars through universities. I believe routine paperwork will kill this project. Such a project should not be owned by universities. It should be run by academics who might be supported by universities. Cooperation across universities should be discussed to exploit as much as we can from the experts and academics in our universities...

Finally, the study recommends that web-conferences be extended to other educational settings, where students in different universities within Saudi Arabia are connected together. Researchers, as well as, graduate students may investigate the use of training web-conferences using a variety of training topics, a stronger focus on part-time employees and larger sample sizes in the future.

\section{REFERENCES}

[1] Angeli, C., Valanides, N. \& Bonk, C. J. (2003). Communication in a web-based conferencing system: The quality of computer-mediated interactions. British Journal of Educational Technology, 34(1), 31-43 Jan 2003.

[2] Artino, A. (2008). Motivational beliefs and perceptions of instructional quality: predicting satisfaction with online training. Journal of Computer Assisted Learning, 24(3), 260-270.

[3] Bandy, J. (2010). When should you offer online training? Performance Improvement, 49(1), 5-6.

[4] Bower, M. \& Hedberg, J. (2010). A quantitative multimodal discourse analysis of teaching and learning in a webconferencing environment--the efficacy of student-centered learning designs. Computers \& Education, 54, 2, 462478 .

[5] Cereijo, M. (2006). Attitude as predictor of success in online training. International Journal on E-Learning, 5(4), 623-639.

[6] Chapman, C. \& Knapczyk, D.(2003).Integrating web conferencing and field work for preparing rural special educators. ERIC Document No. ED476217 
[7] Coffey, J. (2010). Web conferencing software in university-level, e-learning-based, technical courses. Journal of Educational Technology Systems, 38(3), 367-381.

[8] Contreras, M. \& Dolan, M. (2006). Participant interaction in a Latin American online leadership training course. INDES Working Paper Series. ERIC Document No. ED493784

[9] Curran, V., Kirby, F., Parsons, E. \& Lockyer, J. (2003). Discourse analysis of computer-mediated conferencing in world wide web-based continuing medical education. Journal of Continuing Education in the Health Professions, 23(4), 229-238.

[10] Daytner, G., Robinson, L., Schneider, C. \& Johanson, J. (2009). Online teacher training: the early childhood technology integrated instructional system--Phase 3. ERIC Document No. ED508427

[11] Doo, M. (2006). A problem in online interpersonal skills training: Do learners practice skills? Open Learning, 21(3), 263-272.

[12] Foreman, J. \& Jenkins, R.(2005). Full-featured web conferencing systems. Innovate Journal of Online Education, $1(4)$.

[13] Forrester, D. (2009). Global connections: Web conferencing tools help educators collaborate anytime, anywhere. Learning \& Leading with Technology, 36(5), 24-25.

[14] Fridrici, M. \& Lohaus, A. (2009). Stress-prevention in secondary schools: online- versus face-to-face-training. Health Education, 109(4), 299-313.

[15] Ghosh, R. \& Githens, R. (2011). Online contract training: Applying organization theory to reconcile competing missions within community colleges. Human Resource Development Review, 10(2), 180-197.

[16] Grant, A. (2009). Webinars at Louisiana virtual school. Principal Leadership, 9 (9), 64-66.

[17] Hartsell, T. \&Yuen, S. (2006). Video streaming in online learning. AACE Journal, 14(1), 31-43.

[18] Johnson, E., Bishop, A., Holt, A., Stirling, J. \& Zane, J. (2001). Reflections in cyberspace: Web conferencing for language teacher education. Australian Journal of Educational Technology, 17(2), 169-86.

[19] Kear, K., Chetwynd, F., Williams, J. \& Donelan, H. (2012). Web conferencing for synchronous online tutorials: Perspectives of tutors using a new medium. Computers \& Education, 58(3), 953-963.

[20] Kingery, R. (2009). Factors predicting nonprofit employees' likelihood of attending online training. Ph.D. Dissertation, University of Louisville. ERIC Document No. ED515768

[21] Knapczyk, D., Frey, T. \& Wall-Marencik, W. (2005). An evaluation of web conferencing in online teacher preparation. Teacher Education and Special Education, 28(2), 114-124.

[22] Kokoc, M., Ozlu, A., Cimer, A. \& Karal, H. (2011). Teachers' views on the potential use of online in-service education and training activities. Turkish Online Journal of Distance Education, 12(4), 68-87.

[23] Lin, S. \& Chiu, C. (2008). Incentive styles, asynchronous online discussion, and vocational training. Journal of Educational Computing Research, 39(4), 363-377.

[24] Long, L., Dubois, C. \& Faley, R. (2009). A case study analysis of factors that influence attrition rates in voluntary online training programs. International Journal on E-Learning, 8(3), 347-359.

[25] Loudon, M. \& Sharp, M. (2006). Online class review: Using streaming-media technology. Journal of College Science Teaching, 36(3), 39-43.

[26] Montgomery, S. (2009). Online Webinars! Interactive Learning where Our Users Are: The Future of Embedded Librarianship. Public Services Quarterly, 6(2-3), 306-311. 
[27] Quilter, S. \& Chester, C. (2001). The relationship between web-based conferencing and instructional outcomes. Inter- national Journal of Instructional Media, 28(1), 13-22.

[28] Reushle, S. \& Loch, B. (2008). Conducting a trial of web conferencing software: Why, how, and perceptions from the coalface. Journal of Distance Education-TOJDE, 9(3), 19-28. ERIC Document No. ED502083

[29] Seufferheld, M. \& Scagnoli, N. (2011). Web conferencing and ICTs to enhance undergraduate science teaching. $E$ Learning and Digital Media, 8(1), 1-7.

[30] Sitzmann, T., Ely, K., Bell, B. \& Bauer, K. (2010).The effects of technical difficulties on learning and attrition during online training. Journal of Experimental Psychology: Applied, 16(3), 281-292.

[31] Skylar, A. (2009). A comparison of asynchronous online text-based lectures and synchronous interactive web conferencing lectures. Issues in Teacher Education, 18(2), 69-84.

[32] Stephens, K. \& Mottet, T. (2008). Interactivity in a web conference training context: Effects on trainers and trainees. Communication Education, 57(1), 88-104.

[33] Supanakorn-Davila, S. \& Bolliger, D. (2012). A preliminary evaluation of instructional effectiveness of online training implemented at a government agency in Thailand. International Journal on E-Learning, 11(1), 73-94.

[34] Wolf, P. (2006). Best practices in the training of faculty to teach online. Journal of Computing in Higher Education, $17(2), 47-78$.

[35] Wynter-Wellington, S. (2010). An assessment of an interactive online training course at a placement and business service. Ed.D. Dissertation, Nova Southeastern University. ERIC Document No. ED518812. 